\title{
Effect of Ascorbate on Covalent Binding of Benzene and Phenol Metabolites to Isolated Tissue Preparations ${ }^{1}$
}

\author{
ROBERT C. SMART AND VINCENT G. ZANNONI \\ Department of Pharmacology and Department of Environmental and Industrial Health. Toxicology Program, \\ University of Michigan, Ann Arbor, Michigan 48109
}

Received June 7, 1984; accepted October 1, 1984

\begin{abstract}
Effect of Ascorbate on Covalent Binding of Benzene and Phenol Metabolites to Isolated Tissue Preparations. SMART, R. C. and ZANNONI, V. G. (1985). Toxicol. Appl. Pharmacol. 77, 334-343. $\left[{ }^{14} \mathrm{C}\right] \mathrm{Phenol}$ and $\left[{ }^{14} \mathrm{C}\right]$ benzene are metabolized in the presence of NADPH and hepatic microsomes isolated from phenobarbital- or benzene-pretreated or untreated guinea pigs to intermediates capable of covalently binding to microsomal protein. When $1 \mathrm{mM}$ ascorbate was included in the incubation mixture containing benzene as the substrate, covalent binding was inhibited by $55 \%$. Increasing the ascorbate concentration to $5 \mathrm{mM}$ inhibited binding by only an additional $17 \%$. In contrast, when phenol was used as the substrate, $1 \mathrm{~mm}$ ascorbate inhibited binding by $95 \%$. When DT-diaphorase was included in the incubation mixture containing benzene as the substrate, binding was inhibited by only $18 \%$. This degree of inhibition is in contrast to $70 \%$ inhibition with phenol. These results indicate that different metabolites are responsible for a portion of the covalent binding depending upon the substrate employed. GSH inhibited covalent binding greater than 95\% with either substrate. The metabolism of phenol to hydroquinone was unaffected by the addition of ascorbate or GSH. The metabolism of benzene to phenol was unaffected by the addition of GSH; however, the addition of ascorbate decreased the formation of phenol by $35 \%$. Tissue ascorbate could be modulated by placing guinea pigs on different dietary intakes of ascorbate. Bone marrow ascorbate concentrations could be modulated 10 -fold without any significant change in the GSH concentrations. Bone marrow isolated from guinea pigs on different dietary intakes of ascorbate were incubated with $\mathrm{H}_{2} \mathrm{O}_{2}$ and phenol. Bone marrow with low ascorbate concentrations displayed 4-fold more covalent binding of phenol equivalents than those with high ascorbate concentrations. This is an example of how the dietary intake of ascorbate can result in a differential response to a potentially toxic event in vitro. (c) 1985 Academic Press. Inc.
\end{abstract}

It has been established for many years that the bone marrow is the target site of benzene toxicity. Chronic exposure to benzene results in hemopoietic disorders such as aplastic anemia (Snyder and Kocsis, 1975; Snyder et al., 1981). In addition, the relationship between benzene exposure and the development of acute myelogenous leukemia in humans has been established (IARC, 1982). It is generally accepted that benzene must undergo

\footnotetext{
${ }^{1}$ This work was supported by Grant 23007 from Hoffmann-La Roche Inc., Nutley, N.J.
}

metabolic activation to produce its toxicity (Andrews et al., 1977; Bolcsak and Nerland, 1983; Nomiyama, 1962; Sammett et al., 1979). Phenol, hydroquinone, and catechol are the major metabolites of benzene (Porteous and Williams, 1949); however, the metabolite responsible for benzene's myelotoxicity is unknown. Covalent binding of reactive intermediates has been reported to be involved in the toxicity or carcinogenicity of a number of xenobiotics (Jollow et al., 1973; Jollow et al., 1974; Miller and Miller, 1971). The activation of benzene metabolites with 
subsequent covalent binding to bone marrow constituents could result in the toxic event.

Tunek et al. (1978) have postulated that a further metabolite of phenol is responsible for the majority of covalent binding when benzene or phenol is incubated with rat hepatic microsomes. We have previously demonstrated that the majority of covalent binding occurring during the metabolism of phenol is due to the oxidized forms of hydroquinone and catechol (Smart and Zannoni, 1984). We have employed an in vitro system using guinea pig hepatic microsomes, NADPH, and benzene or phenol to determine if the metabolites that covalently bind are the same with either substrate. This determination was accomplished by comparing the degree in which various agents or enzymes could inhibit covalent binding of the metabolites of phenol vs the metabolites of benzene.

Guinea pigs have been reported to be susceptible to the myelotoxic effects of benzene as determined by decreases in circulating blood cells (Das et al., 1969; Wolf et al., 1956). Studies in a variety of laboratories have demonstrated that ascorbate is capable of preventing covalent binding of numerous reactive intermediates (Corcoran et al., 1980; Sawahata and Neal, 1983; Smart and Zannoni, 1984). Agents which can prevent covalent binding are of interest since they may alter toxicity in vivo. The present study also explores the effect of endogenous tissue ascorbate in preventing the in vitro covalent binding of phenol equivalents using bone marrow preparations isolated from pair-fed guinea pigs on different dietary intakes of ascorbate. Since the guinea pig is similar to man in that it cannot synthesize this vitamin, it is an excellent model to modulate the ascorbate concentration in a variety of tissues by controlling the diet.

\section{METHODS}

Chemicals. Phenol and dicumarol were purchased from Aldrich Chemical Company, (Milwaukee, Wisc.), $\left[{ }^{14} \mathrm{C}\right] \mathrm{Phenol}(8.3 \mathrm{mCi} / \mathrm{mmol})$ and $\left[{ }^{14} \mathrm{C}\right]$ benzene $(57.4$
$\mathrm{mCi} / \mathrm{mmol}$ ) were purchased from New England Nuclear Corporation (Boston, Mass.). Specific activity of phenol was adjusted to $0.16 \mathrm{mCi} / \mathrm{mmol}$ and benzene to 0.4 $\mathrm{mCi} / \mathrm{mmol}$. [ $\left.{ }^{14} \mathrm{C}\right] \mathrm{Phenol}$ was extracted from the benzene solution as previously described (Smart and Zannoni, 1984). The radiochemical purity of both phenol and benzene was $>98 \%$. Sodium ascorbate was purchased from Sigma Chemical Company (St. Louis, Mo.). Reduced glutathione, $3 \%$ hydrogen peroxide, benzene, and $\alpha, \alpha^{\prime}$-dipyridyl were purchased from Fisher Scientific Company (Fair Lawn, N.J.). ACS scintillation mixture was purchased from Amersham (Arlington Heights, Ill.).

Dietary ascorbate regimens. Three groups of five to six male Hartley guinea pigs ( 200 to $250 \mathrm{~g}$, Michigan State Department of Health, East Lansing, Mich.) were placed on thrce different dictary intakes of ascorbate; $1.0,0.35$, and $0.05 \mathrm{mg}$ ascorbate $/ \mathrm{ml}$ drinking water for 4 weeks. All groups received ascorbate-deficient guinea pig chow ad libitum (ICN Nutritional Biochemicals, Cleveland, Ohio) and were housed at $22 \pm 2{ }^{\circ} \mathrm{C}$ on a 12 $\mathrm{hr}$ light cycle. The growth curves for the duration of the feeding were similar for the three groups. The group receiving the lowest amount of ascorbate, $0.05 \mathrm{mg} / \mathrm{ml}$ in their drinking water, showed no signs of ascorbate deficiency, i.e., hemorrhages or weight loss. It can be estimated that the guinea pigs in this group consumed at least 1.5 $\mathrm{mg}$ ascorbate animal ${ }^{-1}$ day $^{-1}$. These three groups were used for the quantitation of ascorbate and GSH in the lungs, liver, and bone marrow. Tissue ascorbate was measured by the method of Zannoni et al. (1974). GSH was measured by the method of Ellman (1959). Another group of guinea pigs was pair-fed and their bone marrow was isolated from individual femurs, which was then used in binding studies with phenol and hydrogen peroxide. Pair-feeding was carried out with ascorbate deficient guinea pig chow for 18 days using two groups of five guinea pigs. One group received $0.5 \mathrm{mg}$ ascorbate $/ \mathrm{ml}$ drinking water, the other received no ascorbate. The bone marrow was isolated from both femurs of each animal, and homogenized individually in $10 \mathrm{vol}$ of 100 mM sodium phosphate buffer, $\mathrm{pH}$ 7.4. Peroxidase activity was measured with guaiacol (Smart and Zannoni, 1984).

Guinea pig pretreatment and preparation of hepatic microsomes. Male Hartley guinea pigs (250 to $350 \mathrm{~g}$ ) were treated with $1 \mathrm{mg}$ of phenobarbital/ml in the drinking water for 5 days or $1.1 \mathrm{~g} / \mathrm{kg}$ benzene ip in an equal volume of corn oil twice, 18 and $24 \mathrm{hr}$ before termination. This dose of benzene was used since it effectively induced benzene metabolism in SpragueDawley rats (Post and Snyder, 1983). Animals were decapitated, and their livers were removed and placed on ice and homogenized in 4 vol $100 \mathrm{mM}$ sodium phosphate buffer, pH 7.4. The homogenates were centrifuged at $15,000 \mathrm{~g}$ for $20 \mathrm{~min}$, and the postmitochondrial supernatant fraction was centrifuged at $100,000 \mathrm{~g}$ for 1 $\mathrm{hr}$ to harvest the microsomes. The microsomes were concentrated four timcs ( 16 to $20 \mathrm{mg}$ protcin $/ \mathrm{ml}$ ) based 
on initial volume of the supernatant fraction. Frozen microsomes stored at $-20^{\circ} \mathrm{C}$ for 3 months maintained activity as determined by the degree of covalent binding of phenol or benzene in the presence of NADPH. Prior to use microsomes were washed with 4 vol buffer, homogenized, and centrifuged at $100,000 \mathrm{~g}$ for $30 \mathrm{~min}$ The supernatant fraction was decanted, and the pellet was brought to 6 to $7 \mathrm{mg}$ protein $/ \mathrm{ml}$. Protein was determined by the method of Lowry et al. (1951), with bovine serum albumin as standard.

Incubation conditions and assay of covalent binding. The incubation mixture consisted of washed microsomes (0.7 to $1.2 \mathrm{mg}$ protein $/ \mathrm{ml}), 1 \mathrm{mM}\left[{ }^{14} \mathrm{C}\right]$ phenol or $1 \mathrm{mM}$ $\left[{ }^{14} \mathrm{C}\right]$ benzene, $1 \mathrm{~mm} \mathrm{NADPH}$, and $100 \mathrm{~mm}$ sodium phosphate buffer, $\mathrm{pH}$ 7.4. The total incubation volume was $1 \mathrm{ml}$. The incubation was carried out for 10 or 15 min at $37^{\circ} \mathrm{C}$ in a Dubnoff shaker at 60 oscillations $/ \mathrm{min}$. Incubation conditions using isolated bone marrow preparations were as follows; $35 \mathrm{mg}$ bone marrow tissue in $100 \mathrm{~mm}$ sodium phosphate buffer, $\mathrm{pH} 7.4$, was incubated with $1 \mathrm{~mm}\left[{ }^{14} \mathrm{C}\right]$ phenol, $8.8 \mathrm{~mm}$ hydrogen peroxide, and $0.7 \mathrm{mg}$ microsomal protein. The total incubation volume was $1 \mathrm{ml}$. The incubation was for $5 \mathrm{~min}$ at $37^{\circ} \mathrm{C}$. Covalent binding was measured by the method of Tunek et al. (1978). The method involves repeated extraction with ethyl acetate followed by precipitation of the protein with ethanol. The protein pellet was washed with an acetone/heptane mixture, and then methanol. The protein pellet was dissolved in sodium hydroxide, heated at $80^{\circ} \mathrm{C}$ for $30 \mathrm{~min}$, and neutralized with $\mathbf{H C l}$, and an aliquot was added to the scintillation mixture and counted. When DT-diaphorase was added to the binding assay, I $\mu \mathrm{M}$ FAD was added to optimize activity (Benson et al., 1980; Smart and Zannoni, 1984). DT-Diaphorase was purified from guinea pig liver as previously described (Smart and Zannoni, 1984).

Quantification of hydroquinone and phenol. The major product of phenol metabolism, hydroquinone, and the major product of benzene metabolism, phenol, were extracted from the incubation mixtures, quantified, and identified by gas chromatographic analyses with authentic standards. Incubation conditions were as described in the previous section, except that the benzene concentration was increased to $10 \mathrm{~mm}$ because quantification of the metabolites at $1 \mathrm{~mm}$ bencene was not possible. The reactions were stopped at various times with ice-cold ethyl acetate and placed on ice. 4-Chlororesorcinol (12.5 $\mu \mathrm{g}$ ) was added to each tube as an internal standard. The samples were centrifuged at $3000 \mathrm{~g}$ for $5 \mathrm{~min}$, and the ethyl acetate fraction was collected. This procedure was repeated three times with $1 \mathrm{ml}$ ethyl acetate. Ethyl acetate was evaporated down to $0.2 \mathrm{ml}$ at room temperature with a gentle stream of nitrogen. Twenty microliters acetic anhydride, $20 \mu \mathrm{l}$ pyridine, and $2.5 \mathrm{ml}$ ethyl ether were added, and the samples were derivatized at $70^{\circ} \mathrm{C}$ for $1 \mathrm{hr}$ or until all the ethyl ether had evaporated and only $0.2 \mathrm{ml}$ ethyl acetate remained. Samples were cooled to room temperature, $0.2 \mathrm{ml} 0.5 \mathrm{~N} \mathrm{NaOH}$ was added to remove excess reagent, the samples were centrifuged, and the aqueous layer was removed. The ethyl acetate phase was washed with $0.2 \mathrm{ml}$ pentane and $0.2 \mathrm{ml}$ distilled water, and centrifuged at $3000 \mathrm{~g}$ for $5 \mathrm{~min} ; \mathrm{l} \mu \mathrm{l}$ was injected into a Varian 3700 gas chromatograph equipped with a flame ionization detector. The column was packed with $1 \%$ SP-1240-DA on 100/120 Supelcoport; the column dimensions were $2 \mathrm{~m} \times 2 \mathrm{~mm}$, and was purchased from Supelco. The injector temperalure was $220^{\circ} \mathrm{C}$; column, $157^{\circ} \mathrm{C}$; and detector, $250^{\circ} \mathrm{C}$; the flow rate was $40 \mathrm{ml} / \mathrm{min}$. For quantification of phenol formation from benzene, the flow rate was decreased to $15 \mathrm{ml} / \mathrm{min}$ and the column temperature was decreased to $120^{\circ} \mathrm{C}$; after the phenol peak, the column temperature was increased to $180^{\circ} \mathrm{C}$ to hasten the elution of the standard. Standard curves were obtained and plotted as the peak height ratios, hydroquinone/4-chlororesorcinol and phenol/4-chlororesorcinol. The ratio of hydroquinone formed from phenol and the ratio of phenol formed from benzene to the standard, 4-chlororesorcinol, provided a direct index of the amount of product formed from the enzymatic incubation of phenol or benzene and NADPH. When NADPH was omitted from this incubation mixture, hydroquinone or phenol could not be detected in the respective incubation mixtures.

Statistical analyses. Statistical analyses were conducted by the Student $t$-test. The level of statistical significance used was $p<0.01$.

\section{RESULTS}

Comparison of the Effect of Ascorbate, GSH, and DT-Diaphorase on the Metabolism and Covalent Binding Using either Benzene or Phenol as Substrates

Both $\left[{ }^{14} \mathrm{C}\right]$ benzene and $\left[{ }^{14} \mathrm{C}\right]$ phenol are metabolized in the presence of NADPH and hepatic microsomes isolated from phenobarbital-pretreated guinea pigs to intermediates capable of covalently binding to microsomal protein in vitro (Table 1). The quantity of covalent binding and metabolite formation was linear for at least $15 \mathrm{~min}$ and proportional to protein concentration. NADPH was required for covalent binding; without it less than $5 \%$ of the binding occurred. Ascorbate and glutathione were capable of significantly inhibiting covalent binding (Table 1). As shown in Fig. 1, when $\left[{ }^{14} \mathrm{C}\right]$ benzene was incubated with hepatic microsomes isolated from benzene-pretreated or untreated guinea 
TABLE 1

EFFect of ascorbate and Glutathione on CoVALent Binding of $\left[{ }^{14} \mathrm{C}\right]$ Phenol OR $\left[{ }^{14} \mathrm{C}\right]$ Benzene MEtabolites to HePatic Microsomal PRotein IN VITRO

\begin{tabular}{cc}
\hline & $\begin{array}{c}\text { Covalent binding } \\
\text { (pmol phenol or } \\
\text { benzene equivalents } \\
\text { bound } 10 \text { min }^{-1} \mathrm{mg} \\
\text { microsomal protein }\end{array}$ \\
\hline Additions & \\
\hline With $\left[{ }^{14}\right.$ C]benzene \\
None (control with \\
NADPH) \\
Ascorbate (1 mM) \\
Glutathione (1 mM) \\
With [ ${ }^{14}$ C]phenol & $299 \pm 34(3)$ \\
None (control with & $33 \pm 22(3)$ \\
NADPH) & \\
Ascorbate (1 mM) & $2527 \pm 123(4)$ \\
Glutathione (1 mM) & $134 \pm 17(4)$ \\
\hline
\end{tabular}

Note. $\left[{ }^{14} \mathrm{C}\right]$ Phenol $(1 \mathrm{mM})$ or $\left[{ }^{14} \mathrm{C}\right]$ benzene $(1 \mathrm{mM})$ were incubated with 0.7 to $1 \mathrm{mg}$ of washed hepatic microsomal protein isolated from phenobarbital-pretreated guinea pigs, NADPH ( $1 \mathrm{~mm}$ ), and sodium phosphate buffer ( $100 \mathrm{mM}$, $\mathrm{pH}$ 7.4). The incubation was carried out for 10 or $15 \mathrm{~min}$ at $37^{\circ} \mathrm{C}$. The total volume was $1 \mathrm{ml}$.

${ }^{a}$ Values are expressed as $\bar{x} \pm \mathrm{SD}$.

${ }^{b}$ The number in parentheses equals the number of experiments done in duplicate.

pigs, ascorbate and glutathione were also capable of inhibiting covalent binding. The amount of covalent binding was significantly greater when microsomes isolated from phenobarbital- or benzene-pretreated guinea pigs were used as compared to microsomes from untreated guinea pigs. However, the amount of binding in the presence of ascorbate or GSH was not significantly different regardless of pretreatment when compared to that when microsomes from untreated guinea pigs were used (Fig. 1). The effect of increasing the concentration of ascorbate on binding is shown in Fig. 2. At a concentration of $1 \mathrm{mM}$ ascorbate covalent binding was inhibited by $55 \%$, while at a concentration of $5 \mathrm{mM}$ binding was only decreased an additional $17 \%$.

A comparison of the effect of various additions on covalent binding of $\left[{ }^{14} \mathrm{C}\right]$ benzene

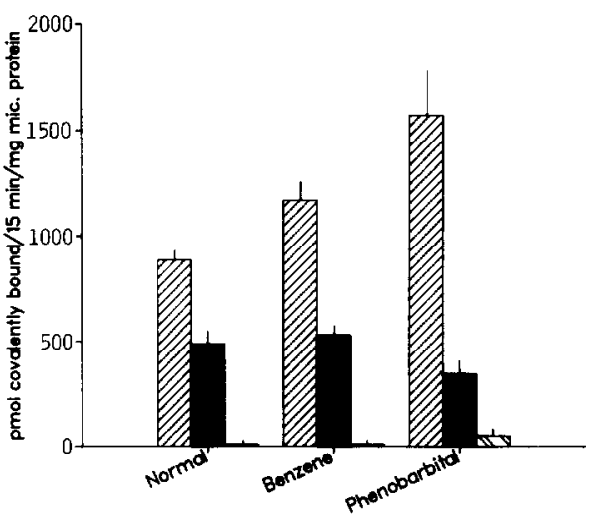

FIG. 1. Inhibition of covalent binding of benzene metabolites by ascorbate or GSH with hepatic microsomes isolated from normal, or benzene-, or phenobarbitalpretreated guinea pigs. $\left[{ }^{14} \mathrm{C}\right]$ Benzene $(1 \mathrm{mM})$ was incubated with 0.7 to $1.0 \mathrm{mg}$ of washed hepatic microsomal protein isolated from untreated, or benzene- or phenobarbital-pretreated guinea pigs, NADPH (1 mM) and sodium phosphate buffer (100 mM, pH 7.4). The incubation was carried out for $15 \mathrm{~min}$ at $37^{\circ} \mathrm{C}$. The total volume was $1 \mathrm{ml}$. $\mathrm{NADPH}$; NADPH $+1 \mathrm{mM}$ ascorbate; NADPH + $1 \mathrm{mM} \mathrm{GSH}$. The pretreatment of animals is given under Methods. Each value represents the mean of three experiments done in duplicate \pm SD.

or $\left[{ }^{14} \mathrm{C}\right]$ phenol is shown in Figs. $3 a$ and $b$. We have previously shown that DT-diaphorase can inhibit covalent binding when phenol and NADPH are incubated with hepatic mi-

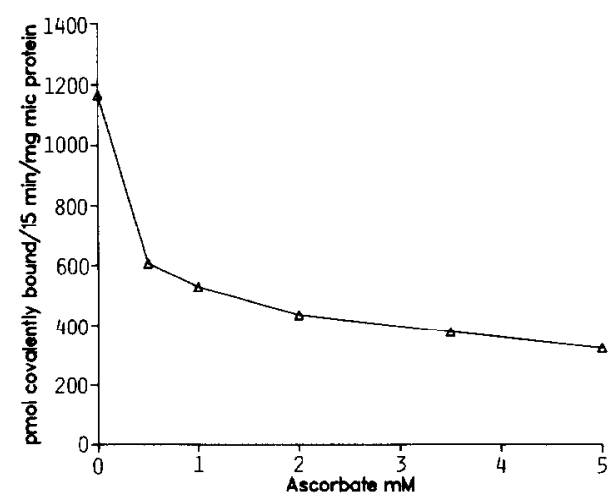

FIG. 2. Effect of varying concentrations of ascorbate on covalent binding of benzene metabolites with microsomes isolated from benzene-pretreated guinea pigs. $\left[{ }^{14} \mathrm{C}\right]$ Benzene $(1 \mathrm{mM})$ was incubated under conditions given in Fig. 1. In addition, the incubation was carried out with various concentrations of ascorbate indicated in the figure. 
crosomes by reducing the metabolites of phenol, $o$ - and $p$-benzoquinone (Smart and Zannoni, 1984). When DT-diaphorase was included in the incubation mixture containing $\left[{ }^{14} \mathrm{C}\right]$ benzene as the substrate, covalent binding was decreased by only $18 \%$ (Fig. 3a). In contrast, when DT-diaphorase was included in the incubation mixture containing $\left[{ }^{14} \mathrm{C}\right]-$ phenol, covalent binding was decreased by $70 \%$ (Fig. 3b). The effect of DT-diaphorase could be reversed with the inclusion of 10 $\mu \mathrm{M}$ dicumarol, a specific inhibitor of DTdiaphorase. When $1 \mathrm{~mm}$ ascorbate was included in the incubation mixture containing $\left[{ }^{14} \mathrm{C}\right]$ benzene or $\left[{ }^{14} \mathrm{C}\right]$ phenol, binding was inhibited by 55 and $95 \%$, respectively (Figs. $3 \mathrm{a}$ and $\mathrm{b}$ ). On the other hand, GSH was effective in inhibiting covalent binding greater than $95 \%$ with either substrate (Figs. 3a and $b$ ).

As shown in Table 2, the inclusion of 1 $\mathrm{mM}$ ascorbate or GSH had no significant effect on the MFO metabolism of phenol to its major metabolite, hydroquinone. However, ascorbate decreased the formation of

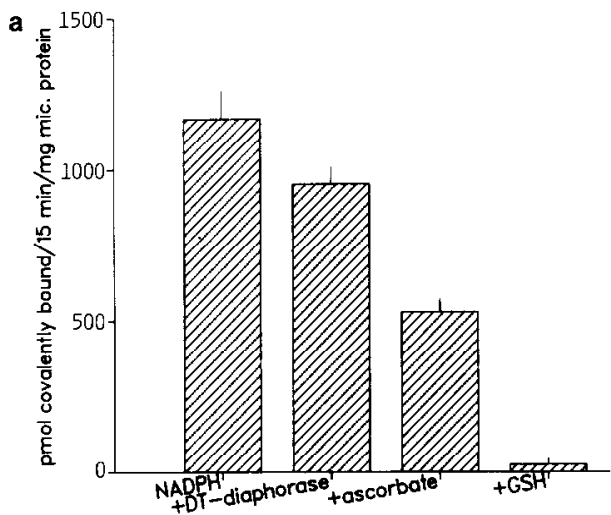

phenol from benzene by $35 \%$, while GSH did not effect the formation of phenol from benzene.

\section{Modulation of Ascorbate Tissue Concentra- tions In Vivo and the Determination of Covalent Binding of Phenol in Isolated Bone Marrow Preparations}

Sincc ascorbate was effective in inhibiting covalent binding with phenol or benzene, it was of interest to determine if the endogenous tissue concentrations of ascorbate could affect covalent binding in isolated bone marrow preparations from guinea pigs on various intakes of dietary ascorbate. To modulate the ascorbate tissue concentrations in vivo, three groups of guinea pigs were fed an ascorbatefree chow diet and various amounts of ascorbate were added to the drinking water. Guinea pigs were terminated after 4 weeks, and ascorbate and GSH concentrations were determined in lung, liver, and bone marrow (Figs. 4 and 5). In the bone marrow, the

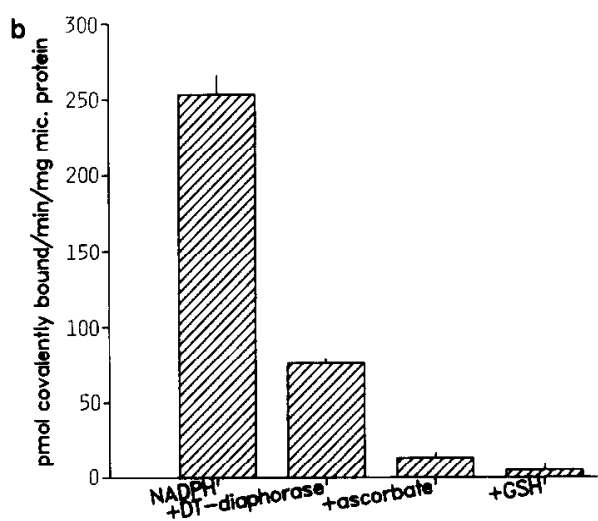

FIG. 3. (a) Effect of DT-diaphorase, ascorbate, or GSH on covalent binding of benzene metabolites with microsomes isolated from benzene-pretreated guinea pigs. $\left[{ }^{14} \mathrm{C}\right]$ Benzene $(1 \mathrm{mM})$ was incubated under conditions given in Fig. 1. In addition, the incubation contained 2 units DT-diaphorase, ascorbate (1 $\mathrm{mM}$ ), or GSH (1 mM). One unit of DT-diaphorase is defined as $1 \mu \mathrm{mol} p$-benzoquinone reduced/min. Each value represents the mean of three experiments done in duplicate \pm SD. (b) Effect of DT-diaphorase, ascorbate, or GSH on covalent binding of phenol metabolites with microsomes isolated from phenobarbitalpretreated guinea pigs. $\left[{ }^{14} \mathrm{C}\right]$ Phenol $(1 \mathrm{mM})$ was incubated under conditions given in Fig. 1 . The incubation time was $10 \mathrm{~min}$. In addition, the incubation contained 2 units DT-diaphorase, ascorbate (1 $\mathrm{mM})$, or GSH ( $1 \mathrm{mM}$ ). One unit of DT-diaphorase is defined as $1 \mu \mathrm{mol} p$-benzoquinone reduced $/ \mathrm{min}$. Each value represents the mean of three experiments done in duplicate $\pm S D$. 
TABLE 2

EFFECT OF AsCORBate AND GLUTATHIONE ON THE Metabolism of Phenol or Benzene by HePatic MICROSOMES

\begin{tabular}{lc}
\hline \multicolumn{1}{c}{ Additions } & $\begin{array}{c}\mathrm{nmol} \text { Phenol formed } \min ^{-1} \\
\mathrm{mg} \text { microsomal protein }\end{array}$ \\
\hline With benzene & \\
None (control with & \\
NADPH) & $2.87 \pm 0.15$ \\
Ascorbate (1 mM) & $1.85 \pm 0.08^{b}$ \\
Glutathione (1 mM) & $2.57 \pm 0.19$ \\
& nmol hydroquinone formed $\min ^{-1}$ \\
& $\mathrm{mg}$ microsomal protein ${ }^{-1} a$ \\
With phenol & \\
None (control with & \\
NADPH) & $2.50 \pm 0.32$ \\
Ascorbate $(1 \mathrm{mM})$ & $2.74 \pm 0.08$ \\
Glutathione $(1 \mathrm{mM})$ & $2.40 \pm 0.21$ \\
\hline
\end{tabular}

Note. Phenol $(1 \mathrm{mM})$ or benzene $(10 \mathrm{~mm})$ were incubated with $1.2 \mathrm{mg}$ of washed hepatic microsomal protein from phenobarbitalpretreated guinea pigs, NADPH (1 mM), and sodium phosphate buffer ( $100 \mathrm{~mm}, \mathrm{pH} 7.4)$. The incubation was carried out for 15 $\min$ at $37^{\circ} \mathrm{C}$. The total volume was $1 \mathrm{ml}$.

${ }^{a}$ Each experiment was done three times, and values are expressed as $\bar{x} \pm \mathrm{SD}$.

${ }^{b}$ Significantly different from the control $(p<0.01)$.

target site of benzene toxicity, the ascorbate tissue concentration could be modulated in the order of 10-fold (Fig. 4), while the GSH

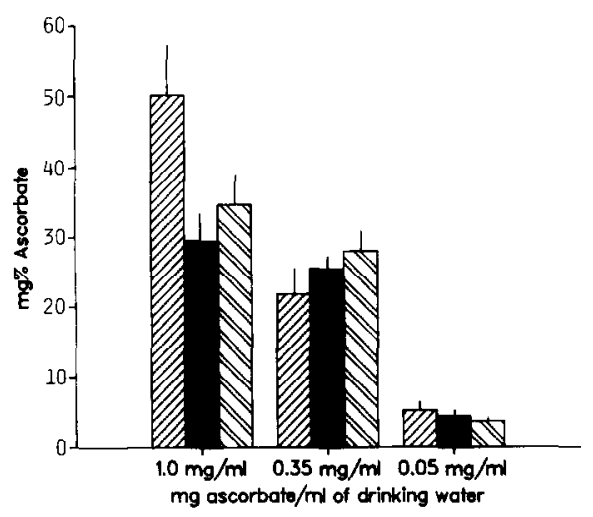

FIG. 4. Ascorbate concentration in liver, lung, and bone marrow in guinea pigs on various dietary regimens of ascorbate. Three groups of guinea pigs were fed varying amounts of ascorbate in their drinking water, as indicated in the figure. All groups received ascorbate-free guinea pig chow for 4 weeks. Tissue concentrations were determined for each individual animal; the data represent $\bar{x} \pm \mathrm{SD}$.

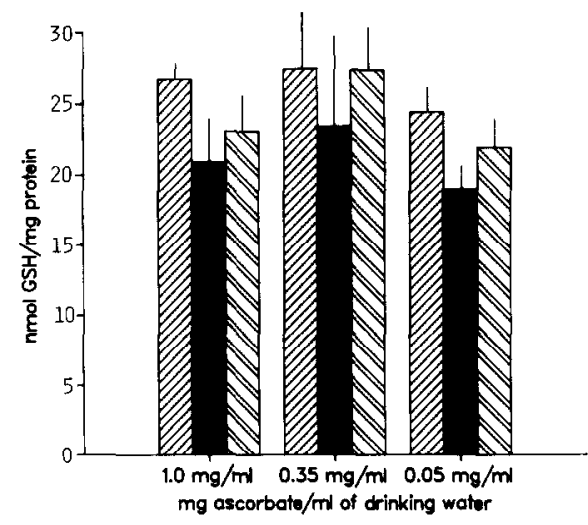

FIG. 5. GSH concentration in liver, lung, and bone marrow in guinea pigs on various dietary regimens of ascorbate. Three groups of guinea pigs were fed varying amounts of ascorbate in their drinking water, as indicated in the figure. liver; $\square$ lung; $\$$ bone marrow. All groups received ascorbate-free guinea pig chow for 4 weeks. Tissue concentrations were determined for each individual animal; the data represent $\bar{x} \pm \mathrm{SD}$.

concentration was not significantly altered (Fig. 5).

We have previously shown that a red blood cell-free myeloperoxidase preparation from guinea pig bone marrow in the presence of hydrogen peroxide is capable of metabolizing phenol to intermediates which covalently bind to protein, and that this binding is inhibited greater than $95 \%$ with $1 \mathrm{mM}$ ascorbate (Smart and Zannoni, 1984). In the present study we have used $\left[{ }^{14} \mathrm{C}\right]$ phenol as a model hydroxylated metabolite of benzene to determine if bone marrow isolated from guinea pigs on different dietary intakes of ascorbate could differentially alter covalent binding of phenol equivalents to protein. Bone marrow was isolated and homogenates were prepared from two groups of guinea pigs which were pair-fed for 18 days on ascorbate-free chow; one group received 0.5 $\mathrm{mg}$ ascorbate/ml drinking water; while the other group did not receive any ascorbate. There was no significant difference in myeloperoxidase activity between the two groups. Oxidation of phenol or guaiacol by these bone marrow homogenates required hydrogen peroxide. Bone marrow homogenates from 
each guinea pig were incubated with $\left[{ }^{14} \mathrm{C}\right]$ phenol and $8.8 \mathrm{mM} \mathrm{H}_{2} \mathrm{O}_{2}$, and subsequent covalent binding of phenol equivalents to protein was quantitated. Covalent binding occurred only if hydrogen peroxide was included in the incubation mixture. As shown in Table 3, covalent binding of phenol equivalents in bone marrow homogenates isolated from guinea pigs on the ascorbate-free diet was 4-fold higher than bone marrow homogenates isolated from the group receiving 0.5 $\mathrm{mg}$ ascorbate/ml drinking water. By comparing the hepatic ascorbate concentrations of each group (Table 3), it can be determined from Fig. 4 that the bone marrow ascorbate concentrations were on the order of 10 -fold higher in the group receiving $0.5 \mathrm{mg}$ ascorbate/ml drinking water. As shown in Fig. 5, there was very little change in GSH concentrations in the bone marrow or liver of guinea pigs on different intakes of ascorbate.

$\left[{ }^{14} \mathrm{C}\right]$ Benzene was incubated under the same conditions as phenol, and subsequent covalent binding was measured. Covalent binding of benzene equivalents to bone marrow protein was equal to or slightly above background binding. This amount of covalent binding using bone marrow preparations with an endogenous low ascorbate concentration was $72.4 \pm 33.4 \mathrm{pmol}$ covalently bound $/ 5$ min, only $2.3 \%$ of that when phenol was used.

\section{DISCUSSION}

We have shown that, when $\left[{ }^{14} \mathrm{C}\right]$ benzene or $\left[{ }^{14} \mathrm{C}\right]$ phenol are incubated with isolated hepatic microsomes and NADPH, GSH, ascorbate, or DT-diaphorase are capable of decreasing covalent binding of the metabolites generated in vitro. Importantly, we have found that the two substrates, benzene and phenol, differ substantially with regard to the ability of ascorbate and DT-diaphorase to inhibit covalent binding of their metabolites. It appears that the metabolites which are binding are different depending upon whether phenol or benzene is used as the substrate. We have shown previously that, when phenol is incubated with NADPH and isolated hepatic microsomes, DT-diaphorase decreases covalent binding by $70 \%$ by reducing 0 - and p-benzoquinone (Smart and Zannoni, 1984). Ascorbate inhibits covalent binding of the metabolites of phenol by $95 \%$ and ascorbate reduces electrophilic quinone species (Corcoran et al., 1980; La Du and Zannoni, 1963). Phenol metabolism, as determined by the formation of hydroquinone, was unaffected by the inclusion of $1 \mathrm{~mm}$ ascorbate, indicating that the decrease in covalent binding is due to the reducing ability of ascorbate. GSH inhibited covalent binding of the metabolites of phenol by $>95 \%$, and also had no effect on the metabolism of phenol. This

TABLE 3

EFFect of Dietary Ascorbate on Covalent Binding of $\left[{ }^{14} \mathrm{C}\right]$ Phenol With Isolated Bone Marrow Preparations from PaIR-Fed Guinea PigS ${ }^{a, b}$

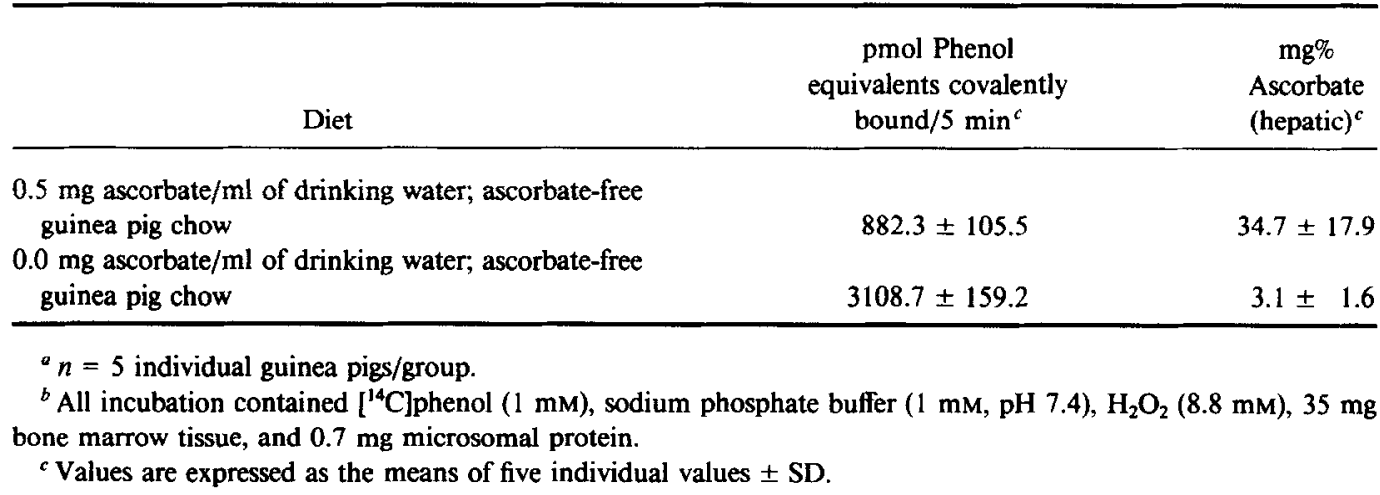


information indicates that the decrease in binding is due to the interaction of GSH with the reactive metabolite(s).

On the other hand, covalent binding occurring during the metabolism of $1 \mathrm{~mm}$ benzene in the presence of ascorbate is decreased from 47 to $71 \%$ depending on if microsomes isolated from untreated, benzenepretreated, or phenobarbital-pretreated guinea pigs were used. In fact, the addition of $5 \mathrm{~mm}$ ascorbate only inhibited covalent binding an additional $17 \%$ when microsomes from benzene-pretreated guinea pigs were used. In contrast to phenol metabolism, the metabolism of benzene was inhibited $35 \%$ by ascorbate as determined by phenol formation when incubated with NADPH, $10 \mathrm{~mm}$ benzene, and microsomes isolated form phenobarbitalpretreated guinea pigs. Assuming that ascorbate is also inhibiting the metabolism of benzene by $35 \%$ when microsomes from untreated or benzene-pretreated guinea pigs are used, the contribution of ascorbate as a reducing agent would range between 17 and $36 \%$. Even if ascorbate had no effect on the metabolism of benzene, there is still a twofold difference between the reducing ability of ascorbate to decrease covalent binding with the metabolites of phenol as opposed to those of benzene. When DT-diaphorase was included in the incubation mixture containing benzene as the substrate covalent binding was decreased by only $18 \%$.

Our results on the effect of ascorbate and DT-diaphorase indicate that the metabolite(s) responsible for a portion of covalent binding when benzene is incubated with guinea pig hepatic microsomes is different than that with phenol. An alternative explanation for this effect could be the differential ability of ascorbate or DT-diaphorase to have access to the reactive metabolite. The large portion of covalent binding occurring during the metabolism of benzene appears to be due to an intermediate prior to the formation of phenol. Tunek et al. (1978) found that GSH inhibited covalent binding when benzene or phenol were incubated with rat liver micro- somes. They postulated that a further metabolite of phenol was responsible for the observed binding when benzene or phenol was used as the substrate. In agreement with Tunek et al. (1978), GSH inhibited binding greater than $95 \%$ with either substrate, and it therefore appears to be a less selective than ascorbate.

Recently, Johansson and Ingelman-Sundberg (1983) have suggested that the covalent binding occurring during the metabolism of benzene is due to the hydroxyl radical-mediated attack of benzene with subsequent covalent binding of the hydroxycyclohexadienyl radical. This metabolite is formed prior to phenol and may be, among others, a candidate in our system. However, the intermediate remains to be elucidated. The significance of this intermediate with regard to myelotoxicity would depend upon the extent of benzene metabolism occurring in the bone marrow. The bone marrow has been reported to contain a small amount of $P-450$ system (Andrews et al., 1979). Irons et al. (1980) have shown that metabolism of the parent compound, benzene, does occur in the bone marrow, but only to a limited extent. The contribution of bone marrow MFO metabolism of benzene to myelotoxicity of benzene remains to be determined.

The bone marrow is the target site of benzene toxicity, and much experimental evidence indicates that the majority of benzene is metabolized by the MFO system in the liver (Andrews et al., 1977; Sammett et al., 1979), and that subsequent metabolites enter the blood stream and accumulate in the bone marrow (Greenlee et al., 1981; Rickert et al., 1979). It is also generally accepted that benzene requires metabolic activation to produce its toxicity (Andrews $e t$ al., 1977; Bolcsak and Nerland, 1983; Nomiyama, 1962; Sammett et al., 1979). Sawahata and Neal (1983) have demonstrated that phenol is oxidized by peroxidases in the presence of hydrogen peroxide to intermediates which covalently bind, and that $o^{\prime}, o$ and $p^{\prime}, p$-biphenol are the major products of 
this reaction. We have demonstrated that the oxidation of phenol by isolated myeloperoxidase with subsequent covalent binding is blocked greater than $95 \%$ by $1 \mathrm{mM}$ ascorbate (Smart and Zannoni, 1984). Since we have demonstrated that ascorbate is generally effective in preventing covalent binding of the metabolites of benzene or phenol, we have determined its effect on covalent binding using bone marrow isolated from guinea pigs on various dictary intakes of ascorbate.

We have presently used phenol as a model hydroxylated metabolite of benzene and have demonstrated a fourfold increase in covalent binding when $\left[{ }^{14} \mathrm{C}\right]$ phenol was incubated with hydrogen peroxide and bone marrow homogenates from guinea pigs with a low ascorbate tissue concentration. Since ascorbate can block the oxidation of phenol and hydrogen peroxide is required for the activation of phenol and for covalent binding, a bone marrow peroxidase (myeloperoxidase) is suspeced as the enzyme responsible for the activation of phenol. Several studies have correlated benzene toxicity with the degree of covalent binding in the bone marrow (Longacre et al., 1981; Sammett et al., 1979). The increase in covalent binding in isolated bone marrow preparations with an endogenous low concentration of ascorbate is an example of a nutritional influence on a potentially toxic event.

\section{REFERENCES}

ANDrews, L. S., LeE, E. W., WitMer, C. M., Kocsis, J. J., AND SNYDER, R. (1977). Effects of toluene on the metabolism, disposition and hemopoietic toxicity of ${ }^{14} \mathrm{C}$-benzene. Biochem. Pharmacol. 26, 293-300.

Andrews, L. S., Sesame, H. A., and Gillette, J. R. (1979). ${ }^{3} \mathrm{H}$-Benzene metabolism in rabbit bone marrow. Life Sci. 25, 567-572.

Benson, A. M., Hunkeler, M. J., And Talalay, P. (1980). Increase in NAD(P)HItinone reductase by dietary antioxidants: Possible role in protection against carcinogenesis and toxicity. Proc. Natl. Acad. Sci. USA 77, 5216-5220.

BOLCSAK, L. E., AND NERLAND, D. E. (1983). Inhibition of erythropoiesis by benzene and benzene metabolites. Toxicol. Appl. Pharmacol. 69, 363-368.
Corcoran, G. B., Mitchell, J. R., Vaishnav, Y. N., AND HoRning, E. C. (1980). Evidence that acetaminophen and $\mathrm{N}$-hydroxyacetaminophen form a common arylating intermediate, $\mathrm{N}$-acetyl-p-benzoquinoneimine. Mol. Pharmacol. 18, 536-549.

Das, K. C., Sen, N. N., ANd Aikat, B. K. (1969). Studies on the development of bone marrow hypoplasia. Part I. Effects of benzene on blood and bone marrow. Ind. Med. Res. 57, 650-669.

EllmaN, G. L. (1959). Tissue sulfhydryl groups. Arch. Biochem. Biophys. 82, 70-77.

Greenlee, W. F., Gross, E. A., AND Irons, R. D. (1981). Relationship between benzene toxicity and disposition of ${ }^{14} \mathrm{C}$-labelled benzene metabolites in the rat. Chem. Biol. Interact. 33, 285-299.

International Agency For Research On Cancer (1982). Monographs on the Evaluation of Carcinogenic Risk of Chemicals to Man: Some Industrial Chemicals and Dyestuffs, pp. 93-148, 395-398. International Agency for Research on Cancer, Lyon.

IRONS, R. D., DENT, J. G., BAKER, T. S., AND RICKERT, D. E. (1980). Benzene is metabolized and covalently bound in bone marrow in situ. Chem. Biol. Interact. 30, 241-245.

JoHANSSUN, I., AND INGELMAN-SUNDBERG, M. (1983). Hydroxyl radical-mediated cytochrome P-450-dependent metabolic activation of benzene in microsomes and reconstituted enzyme systems from rabbit liver. J. Biol. Chem. 258, 7311-7316.

Jollow, D. J., Mitchell, J. R., POTter, W. Z., DAVIS, D. C., Gillette, J. R., ANd Brodie, B. B. (1973). Acetaminophen-induced hepatic necrosis. II. Role of covalent binding in vivo. J. Pharmacol. Exp. Ther. 187, 195-202.

Jollow, D. J., Mitchell, J. R., Zampaglione, N., AND GILLETTE, J. R. (1974). Bromobenzene-induced liver necrosis. Protective role of glutathione and evidence for 3,4-bromobenzene oxide as the hepatotoxic metabolite, Pharmacology 11, 151-169.

LA DU, B. N., AND ZANNONI, V. G. (1963). Oxidation of homogentisic acid catalyzed by horseradish peroxidase. Biochim. Biophys. Acta 67, 281-287.

LONGACRE, S. L., KoCsis, J. J., AND SNYDER, R. (1981). Influence of strain differences in mice on the metabolism and toxicity of benzene. Toxicol. Appl. Pharmacol. 60, 398-409.

Lowry, O. H., Rosebrough, N. J., FarR, A. L., AND RANDELl, R. J. (1951). Protein determination with the Folin phenol reagent. J. Biol. Chem. 193, 265275.

Miller, J. A., ANd Miller, E. C. (1971). Chemical carcinogenesis: Mechanisms and approaches to its control. J. Natl. Cancer Inst. 47, 5-13.

NomiYama, K. (1962). Studies on the poisoning by benzene and its homologues. Oxidation rate of benzene and benzene poisoning. Med. J. Shinshu Univ. 7, 4148. 
Porteous, J. W., AND Williams, R. T. (1949). Studies in detoxication 19. I. (a) The determination of phenol in urine with 2:6dichloroquinonechloroimide. (b) The excretion of phenol, glucuronic acid, and etheral sulphate by rabbits receiving benzene or phenol. (c) Observations on the determination of catechol, quinone and muconic acid in urine. Biochem. J. 44, 46-55.

Post, G. B., AND SNYDER, R. (1983). Effects of enzyme induction on microsomal benzene metabolism. $J$. Toxicol. Environ. Health 11, 811-825.

RickerT, D. E., BaKer, T. S., Bus, J. S., Barrow, C. S., AND IRONS, R. D. (1979). Benzene disposition in the rat after exposure by inhalation. Toxicol. Appl. Pharmacol. 49, 417-423.

SAMmeTt, D., LeE, E. W., Kocsis, J. J., AND SNYdeR, R. (1979). Partial hepatectomy reduces both metabolism and toxicity of benzene. J. Toxicol. Environ. Health 5, 785-792.

SawAHATA, T., AND NEAL, R. A. (1983). Biotransformation of phenol to hydroquinone and catechol by rat liver microsomes. Mol. Pharmacol. 23, 453-460.

Sawahata, T., and Neal, R. A. (1982). Horseradish peroxidase-mediated oxidation of phenol. Biochem. Biophys. Res. Commun. 109, 988-994.

SMART, R. C., AND ZANNONI, V. G. (1984). DT-Dia- phorase and peroxidase influence the covalent binding of the metabolites of phenol, the major metabolite of benzene. Mol. Pharmacol. 26, 105-111.

SNYDER, R., AND KocsIs, J. J. (1975). Current concepts of chronic benzene toxicity. CRC Crit. Rev. Toxicol. 3, 265-288.

SNYDeR, R., LONGaCRE, S. L., WITMER, C. M., Kocsis, J. J., ANDREWs, L. S., AND LEE, E. W. (1981). Biochemical toxicology of benzene. In Reviews in Biochemical Toxicology (E. Hodgson, J. R. Bend, and R. M. Philpot, eds.), Vol. 3, pp. 123-153. Elsevier/ North-Holland, New York/Amsterdam.

TUNeK, A., Platt, K. L., Bentley, P., AND OesCh, F. (1978). Microsomal metabolism of benzene to species irreversibly binding to microsomal protein and effects of modification of this metabolism. Mol. Pharmacol. 14, 920-929.

Wolfe, M. A., Rowe, V. K., MoCollister, D. D., HOLLINGSWORTH, R. L., AND OYEN, F. (1956). Toxicological studies of certain alkylated benzenes and benzene. AMA Arch. Ind. Health 14, 387-398.

ZanNONI, V., LynCH, M., Goldstein, S., and SATO, P. (1974). A rapid micromethod for the determination of ascorbic acid in plasma and tissues. Biochem. Med. 11, 41-48. 